\title{
Quantitative Research on the Role of Large Precipitates in V-Ti Micro-Alloyed Steel during Dynamic Transformation
}

\author{
Da-Yong Wu $\cdot$ Fu-Ren Xiao $\cdot$ Lai-Lei Wu $\cdot$ Ming-Yu Sun $\cdot$ Bo Liao
}

Received: 28 February 2014/Revised: 17 April 2014/Published online: 16 November 2014

(C) The Chinese Society for Metals and Springer-Verlag Berlin Heidelberg 2014

\begin{abstract}
To research the effect of large precipitates (size $>0.2 \mu \mathrm{m}$ ) on strain-induced dynamic transformation, the variation of $\mathrm{V}$ contents in large precipitates has been investigated quantitatively in two V-Ti micro-alloyed steels. The results showed that high $\mathrm{N}$ content promoted $\mathrm{V}$ precipitation on the surface of Ti large precipitates rapidly. Subsequently, large precipitates containing $\mathrm{V}$ induced the formation of intragranular ferrite, which accelerated the dynamic transformation process remarkably, promoted the occurrence of continuous dynamic recrystallization of ferrite and improved the refinement effect.
\end{abstract}

KEY WORDS: Transformation; Precipitates; Intragranular ferrite; Recrystallization; EBSD

\section{Introduction}

Grain refinement is well known as the most prevalent way of achieving high strength in metallic materials without losing toughness and ductility [1, 2]. Strain-induced dynamic transformation has been proved to be one of the most promising fabrication processes for ultrafine-grained metallic materials because of its low-cost simplicity and efficiency in grain refinement [3, 4]. Adachi et al. [5] reported that ultrafine-grained ferrite structure could be successfully achieved in a wide range of steel compositions through the austenite region and cooling route. Ferrite transformation is dynamically induced through the increase in austenite-free energy and potential nucleation site density during the course of deformation. Therefore, lots of investigations have been carried out on rolling conditions

Available online at http://link.springer.com/journal/40195

D.-Y. Wu · F.-R. Xiao · L.-L. Wu · M.-Y. Sun · B. Liao $(\bowtie)$

The Key Laboratory of Metastable Materials Science \&

Technology, College of Materials Science and Engineering,

Yanshan University, Qinhuangdao 066004, China

e-mail: frxiao@ysu.edu.cn; cyddjyjs@263.net such as deformation temperature, strain and strain rate in recent years [6, 7]. Similarly, grain refinement by dynamic transformation is strongly dependent on the chemical composition of steels, especially the addition of $\mathrm{V}, \mathrm{Ti}$ and $\mathrm{Nb}$, which can precipitate during dynamic transformation. Eghbali and Abdollah-Zadeh [8] investigated ferrite grain refinement for low-carbon $\mathrm{Nb}$-micro-alloyed steels in connection with dynamic transformation and showed that $\mathrm{Nb}$ addition delayed austenite recrystallization, allowing the dynamic transformation of ferrite to form at a relatively high rolling temperature. Wang et al. [9] reported V carbonitrides rapidly precipitating due to strain-induced precipitation during deformation, which caused a decrease in $\mathrm{V}$ dissolved in matrix and indirectly accelerating dynamic transformation. Meanwhile, carbonitrides could act as a ferrite nucleus. The work by Medina et al. [10] revealed that the intragranular nucleation of ferrite on the precipitates led to a significant decrease in grain size, close to $50 \%$. Hu et al. [11] researched the ferrite nucleation behaviour on the $(\mathrm{Ti}, \mathrm{V})(\mathrm{C}, \mathrm{N})$ complex precipitates and the results showed that grain size was refined from 5 to $2.5 \mu \mathrm{m}$, and the yield strength increased by $102 \mathrm{MPa}$ due to the addition of $0.1 \mathrm{wt} \% \mathrm{~V}$ and $0.2 \mathrm{wt} \%$ Ti micro-alloyed steel. However, intragranular ferrite formed and the 
Table 1 Chemical compositions of the two tested steels (wt\%)

\begin{tabular}{llllllllll}
\hline Steel & $\mathrm{C}$ & $\mathrm{Si}$ & $\mathrm{Mn}$ & $\mathrm{P}$ & $\mathrm{S}$ & $\mathrm{Ti}$ & $\mathrm{V}$ & $\mathrm{N}$ & $\mathrm{Fe}$ \\
\hline $\mathrm{A}$ & 0.084 & 0.66 & 1.28 & 0.0065 & 0.0033 & 0.020 & 0.088 & 0.0051 & Bal. \\
B & 0.086 & 0.66 & 1.4 & 0.0065 & 0.0030 & 0.020 & 0.053 & 0.015 & Bal. \\
\hline
\end{tabular}
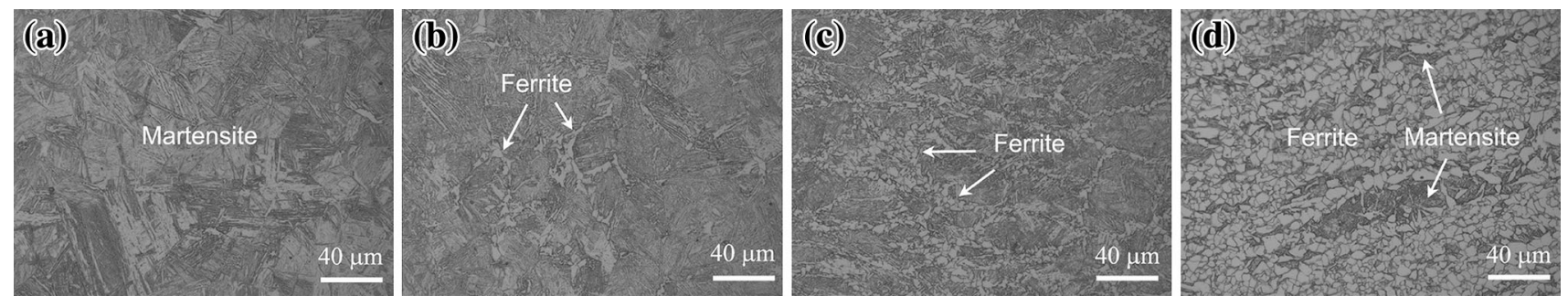

Fig. 1 Optical micrographs of steels $\mathrm{A}$ and $\mathrm{B}$ deformed at $870{ }^{\circ} \mathrm{C}$ under different strains: a steel $\mathrm{A}, \varepsilon=0.22 ; \mathbf{b}$ steel A, $\varepsilon=0.60$; $\mathbf{c}$ steel $\mathrm{B}$, $\varepsilon=0.22 ; \mathbf{d}$ steel $\mathrm{B}, \varepsilon=0.60$

evolution of precipitate during dynamic transformation have not been investigated or analysed.

In the present study, the large precipitates were filtered via a microfiltration membrane $(98 \%$ pore diameter $<200 \mathrm{~nm}$ ) after dissolving the samples. The pore diameter was selected according to the critical size and most effective inclusions necessary for intragranular ferrite $(0.2 \mu \mathrm{m}[11]$ and $0.4-3 \mu \mathrm{m}[12])$. The filtered precipitates were characterized by scanning electron microscopy (SEM) and measured by ICP-AES after dissolving. Combined with the microstructure observation, the effect of large precipitates on the microstructure during dynamic transformation was discussed.

\section{Experimental}

The testing steels were smelted by vacuum induction furnace, and then forged to steel bars of $\Phi 12 \mathrm{~mm}$. The hotforged bars were austenitized at $1,150{ }^{\circ} \mathrm{C}$ for $2 \mathrm{~h}$ and then air-cooled to room temperature. The chemical composition of tested steels is listed in Table 1. In order to compare different amounts of precipitation, a higher $\mathrm{N}$ content was designed in steel B to increase the precipitating trend [10, 13]. The austenite-ferrite equilibrium transformation temperatures $\left(A_{\mathrm{e} 3}\right)$ for the steels were approximately equal to $863^{\circ} \mathrm{C}$, which was calculated by Thermo-Calc software. In this work, a temperature slightly higher than $A_{\mathrm{e} 3}$ of $870{ }^{\circ} \mathrm{C}$ was selected, at which the dynamic transformation could happen and the different precipitation conditions in the two steels could be found. It should be pointed out that the effect of temperature on dynamic transformation was not considered in this paper. Cylindrical samples of $8 \mathrm{~mm} \times 12 \mathrm{~mm}$ were machined from the bars. The deformation tests were performed on a Gleeble-3500 thermo-mechanical simulator. After being austenitized at $1,150{ }^{\circ} \mathrm{C}$ for $300 \mathrm{~s}$, the samples were cooled to $870{ }^{\circ} \mathrm{C}$ at a cooling rate of $10{ }^{\circ} \mathrm{C} / \mathrm{s}$ with a soaking time of $10 \mathrm{~s}$ at this temperature in order to equilibrate the temperature within the samples. After holding for $10 \mathrm{~s}$, quenched samples were used to detect prior austenite grain size, and approximately 35 and $38 \mu \mathrm{m}$ were obtained for steel A and $\mathrm{B}$, respectively. In addition, no ferrite formed isothermally was found in these quenched samples. Other samples were deformed at a constant strain rate of $1.0 \mathrm{~s}^{-1}$ to a prescribed diametrical strain. After deformation, the specimens were immediately water-quenched to room temperature. The specimens were observed by means of optical microscopy and SEM. Thin foils were made from a selection of the samples by electropolishing and these were examined under a JEM-2010 TEM at $200 \mathrm{kV}$. The grain size was measured by applying ASTM standard E-112. The orientation evolution of grains was investigated using an electron back-scattering diffraction (EBSD) analyser. From every sample, $10 \mathrm{~g}$ of powder was obtained by weighing with an electronic balance after drilling with a bench drill. These powders were dissolved in $50 \% \mathrm{HCl}$ and filtered via a microfiltration membrane, and then the particles were observed using SEM and measured by ICP-AES.

\section{Results and Discussion}

Figure 1 shows the optical microstructures of the experimental steels quenched at $870{ }^{\circ} \mathrm{C}$ under strains of 0.22 and 0.60 . Figure 2 exhibits the variation of $f_{\alpha}$ with the increasing strain. When the strain was 0.22 , there was no ferrite transformation in steel $\mathrm{A}$, whereas polygonal ferrite 


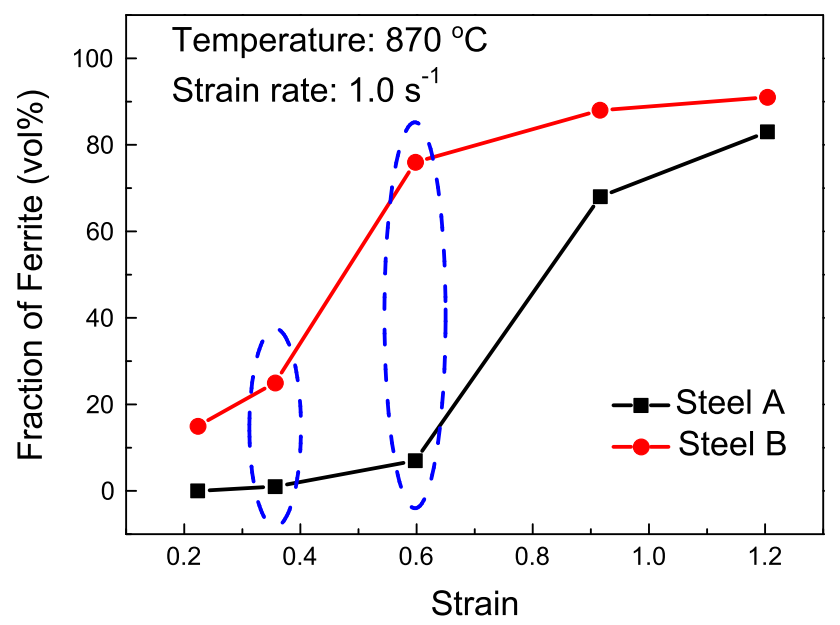

Fig. 2 The evolution of ferrite fraction $\left(f_{\alpha}\right)$ with the strain for the tested steels

along the austenite grain boundary was observed in steel B. As the strain increased to 0.60 , film-shaped ferrite was observed in steel A, which indicated that the dynamic transformation had just begun. However, when the strain was 0.60 , the ferrite transformation within the austenite grain began to accelerate so that the amount of polygonal ferrite rapidly increased in steel $\mathrm{B}$. The significantly different amounts of ferrite between steels A and B could be mainly attributed to the generation of intragranular ferrite due to the different $\mathrm{V}, \mathrm{N}$ contents between the steels, which can precipitate as nucleation sites for intragranular ferrite.

Figure 3 shows the SEM image and EDS analysis results of the large precipitate. According to the observation of the SEM morphologies for the large precipitate, the particle exhibited a rectangular shape, which was characteristic of $\mathrm{Ti}(\mathrm{C}, \mathrm{N})[14,15]$. Combined with the EDS analysis, the particles were determined to be ( $\mathrm{Ti}$, $\mathrm{V})(\mathrm{C}, \mathrm{N})$ while $\mathrm{V}$ should precipitate on the surface of $\mathrm{Ti}(\mathrm{C}, \mathrm{N})$. According to Eqs. (1) and (2) [16], the complete dissolution temperatures of $\mathrm{TiN}$ and $\mathrm{TiC}$ in steel $\mathrm{B}$ are 1,808 and $1,239^{\circ} \mathrm{C}$. Therefore, Ti should not be dissolved completely in steel $\mathrm{B}$ at $1,150{ }^{\circ} \mathrm{C}$, which means that there were many undissolved $\mathrm{Ti}$ large precipitates in steel B before deformation. For the same
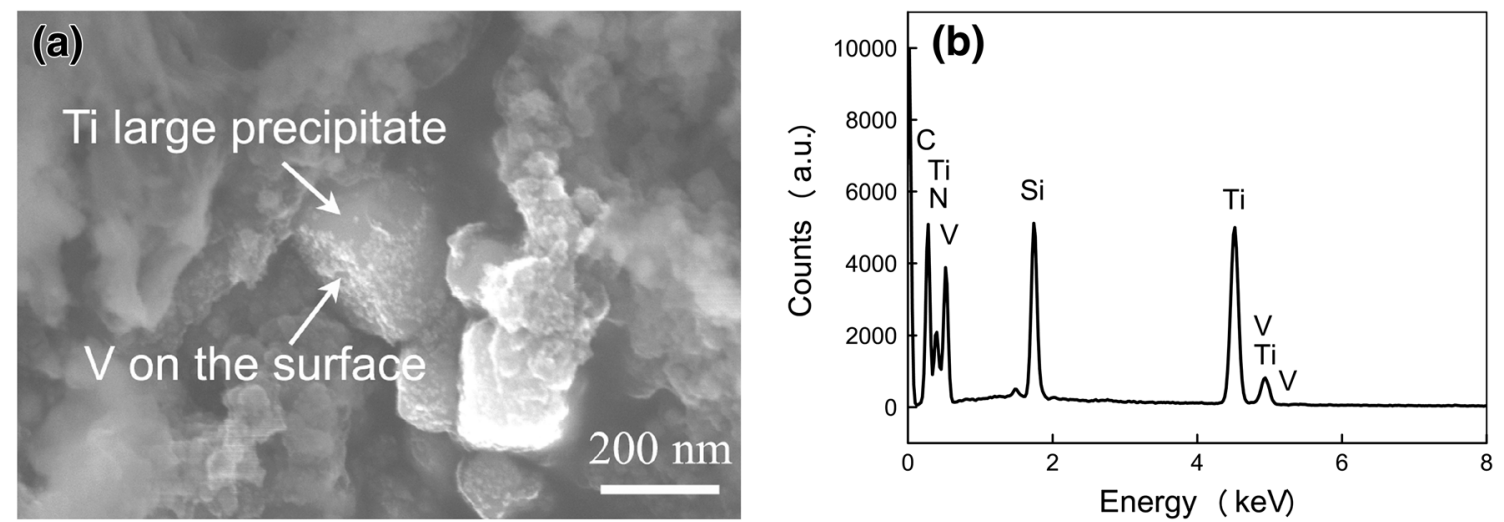

Fig. 3 SEM image a, EDS analysis result $\mathbf{b}$ of a large precipitate obtained in steel B under strain of 0.6
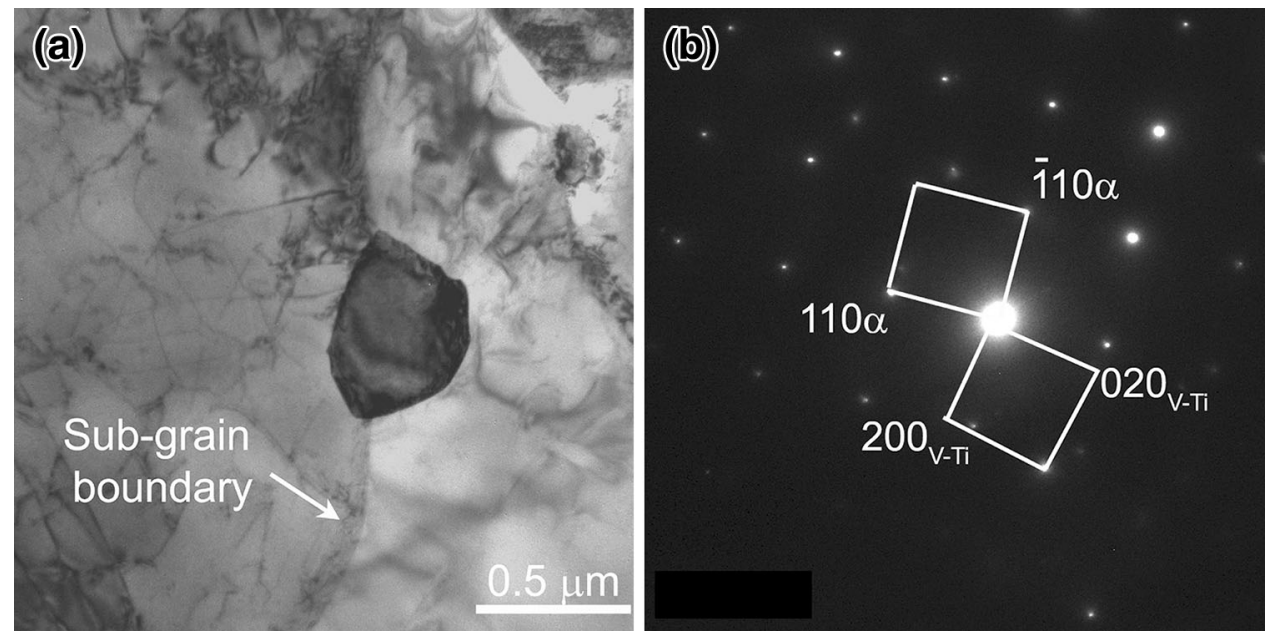

Fig. 4 TEM image a, SADP $\mathbf{b}$ of a large precipitate obtained in steel B under strain of 0.6 

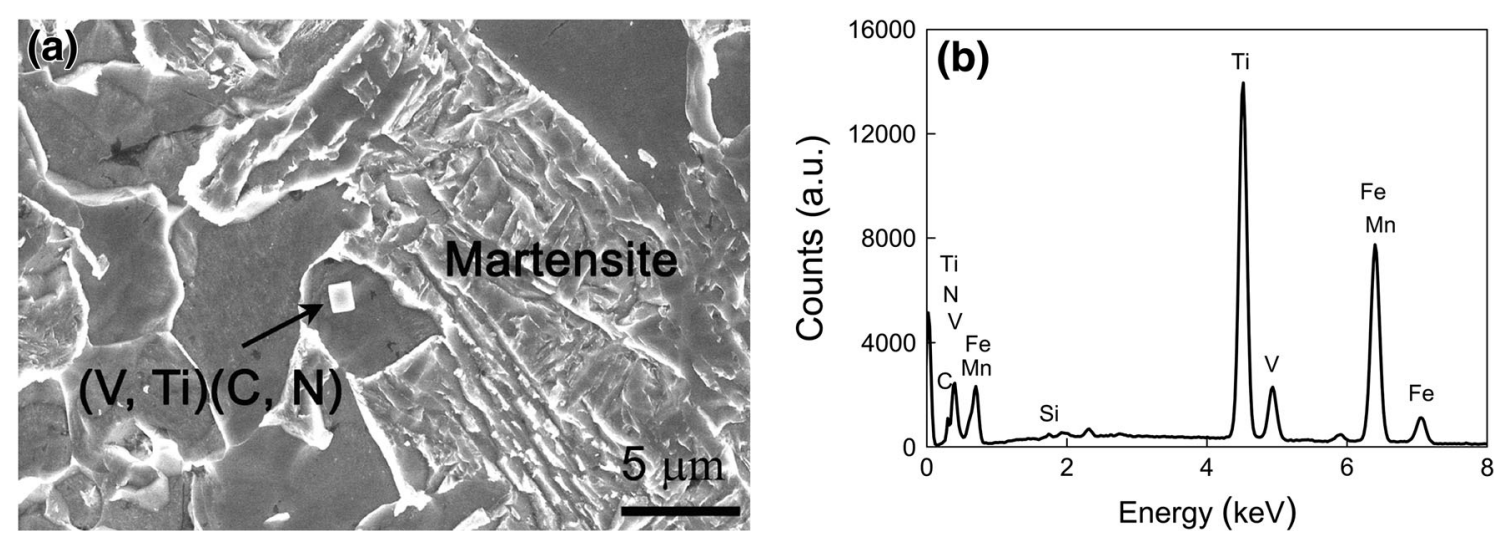

Fig. 5 SEM image a, EDS analysis result $\mathbf{b}$ of a large precipitate obtained in steel B under strain of 0.6
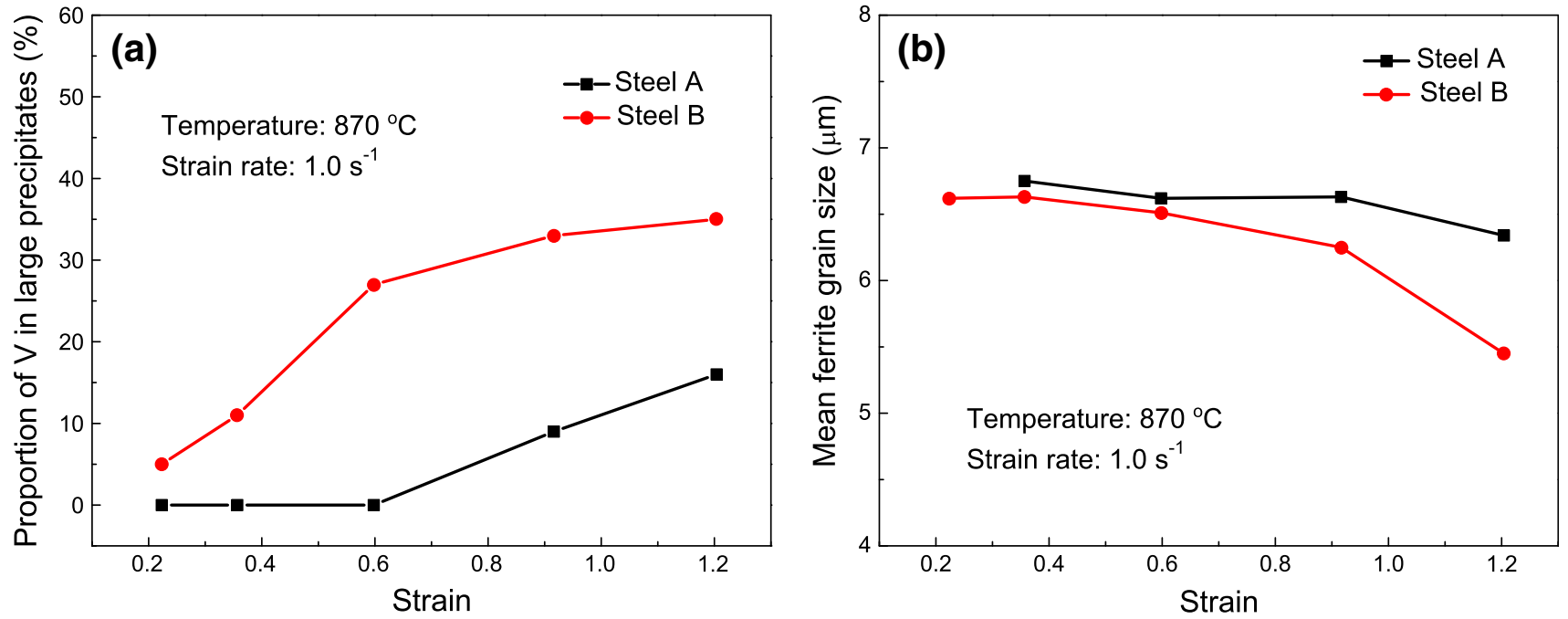

Fig. 6 Proportion of V in the large precipitates of the total content measured by ICP-AES a, the mean ferrite sizes $\mathbf{b}$ of the steels A and B under different strains

reason, high $\mathrm{Ti}$ content in large precipitates in steel $\mathrm{A}$ was detected. According to Eqs. (3) and (4) [17], the complete dissolution temperatures of $\mathrm{VN}$ and $\mathrm{VC}$ in steel $\mathrm{B}$ are 992 and $759^{\circ} \mathrm{C}$. VN has a higher dissolution temperature than $\mathrm{VC}$, but both are much lower than $\mathrm{Ti}$ particles. However, the existence of $\mathrm{Ti}$ and $\mathrm{N}$ can increase the precipitation temperature of $\mathrm{VC}$, and the precipitation of VC could also be stimulated by heavy deformation. Generally, most $\mathrm{V}$ precipitated on the dislocation and grain boundary [18]. With the pre-existence of $\mathrm{Ti}$ particles and the small lattice mismatch of $\mathrm{VN}$ with TiN, V carbonitrides could rapidly precipitate on the surface of Ti large precipitates. Therefore, there is always $\mathrm{Ti}(\mathrm{C}, \mathrm{N})$ during the whole hot working process, and the $\mathrm{V}(\mathrm{C}, \mathrm{N})$ forms on the surface of $\mathrm{Ti}(\mathrm{C}, \mathrm{N})$ by strain-induced precipitation.

$\log [\mathrm{Ti}][\mathrm{C}]=\frac{-7,000}{T}+2.75$, $\log [\mathrm{Ti}][\mathrm{N}]=\frac{-8,000}{T}+0.32$

$\log [\mathrm{V}][\mathrm{C}]=\frac{-9,500}{T}+6.72$,

$\log [\mathrm{V}][\mathrm{N}]=\frac{-8,330}{T}+3.46$,

where [Ti], [C], [N] and [V] are the content values (in wt\%) of $\mathrm{Ti}, \mathrm{C}, \mathrm{N}$ and $\mathrm{V} ; \mathrm{T}$ is the temperature in $\mathrm{K}$.

Figure 4 shows a TEM image of a large precipitate observed in steel B under strain 0.6 and corresponding diffraction pattern. According to the diffraction pattern analysis, the outer layer of the particle was V-rich precipitate. Figure 5 shows a SEM image in which a relatively large precipitate can be seen inside a ferrite grain well below the average size, it being highly possible that this precipitate may have served as a source for the nucleation of this grain. 

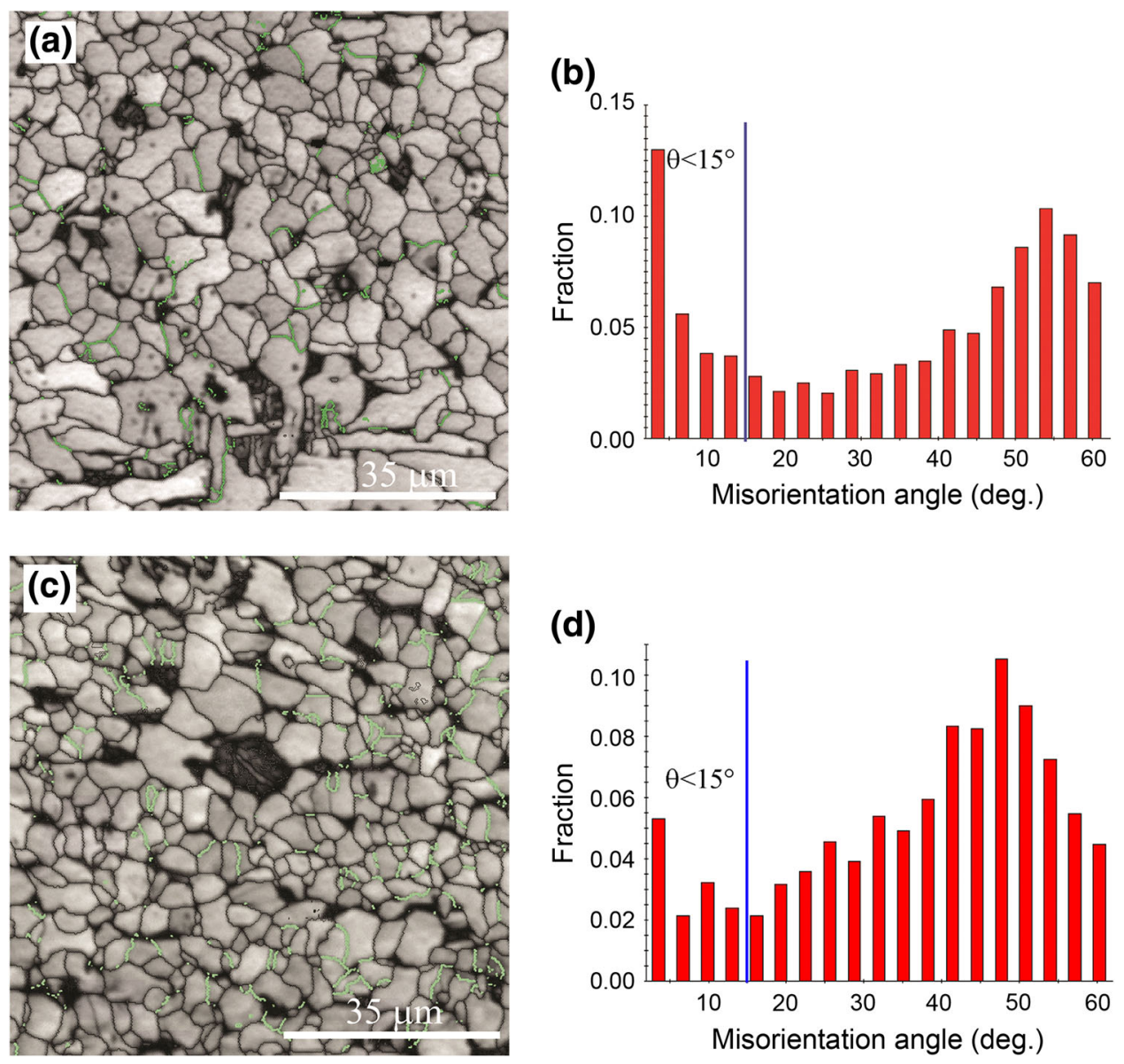

Fig. 7 Boundary misorientation maps and distribution misorientation angles between adjacent ferrite grains for steel B under the strains of 0.91 a, b, $1.20 \mathbf{c}, \mathbf{d}$

For intragranular ferrite nucleation potency, an early work by Gregg and Bhadeshia [19] concluded that TiN made little contribution to promote ferrite transformation in carbon steels, based on the results of controlled experiments with steel-ceramic pressure-bonded specimens and mineral phase powder added steel, also proved by the experiment of Shim et al. [20]. TiN particles are less potent as nucleation sites, since the ratio of crystal lattice misfit to ferrite is $3.8 \%$ and in the case of $\mathrm{VN}$ is $1.3 \%$. The very small lattice mismatch of VN with ferrite facilitates ferrite nucleation and low interfacial energy $[11,13]$. Therefore, the $\mathrm{V}$ precipitated at the surface of $\mathrm{Ti}(\mathrm{C}, \mathrm{N})$ played an important role in the formation of intragranular ferrite, and the $\mathrm{Ti}$ precipitation was mainly for meeting the particle size requirement for intragranular ferrite. According to Furuhara et al. [13], the addition of $\mathrm{N}$ would greatly enhance the $\mathrm{V}$ precipitation, especially at higher temperature. Hence, comparing the composition of the tested steels, more intragranular ferrite would be formed in steel B due to much higher $\mathrm{N}$ content, which explains the accelerated dynamic transformation process in steel B (Fig. 2).
In addition, it is necessary to point out that the more ferrite induced by deformation in steel B was not all intragranular ferrite. Enomoto et al. [21] have suggested that the segregation of $\mathrm{V}$ to austenite grain boundaries and the formation of atom clusters with $\mathrm{C}$ (as a precursor of precipitation) can be considered as possible causes of ferrite nucleation. Therefore, another factor for accelerating dynamic transformation should be the decrease of $\mathrm{C}$ and $\mathrm{V}$ dissolved in austenite matrix due to $\mathrm{V}$ precipitation.

Figure 6a shows the variation of the percentage of $\mathrm{V}$ precipitated in large precipitates from the total. When the strain increased from 0.22 to 1.20 , the $\mathrm{V}$ content in the large precipitates increased from 5 to $35 \%$ of the total in steel B. However, V hardly precipitated in large precipitates for steel A when the strain was 0.60 . Figure $6 \mathrm{~b}$ shows the variation of mean grain size $\left(d_{\alpha}\right)$ with strain. Zheng et al. [22] demonstrated that the ferrite refinement by dynamic transformation is the result of the increasing ferrite nuclei density by "unsaturated nucleation" and limited ferrite growth because of the fast redistribution of carbon. However, in this work, the $d_{\alpha}$ of steel B owing to forming 
more intragranular ferrite decreased slowly at the middle deformation stage when a mass of intragranular ferrite (as shown in Fig. 5) was observed. Meanwhile, the $d_{\alpha}$ of steel B was only a little smaller than steel A. This suggested that the perceived ferrite refinement enhanced by the appearance of $(\mathrm{Ti}, \mathrm{V})(\mathrm{C}, \mathrm{N})$, which increased ferrite nucleation sites, was not remarkable during dynamic transformation. Nevertheless, a more obvious decrease of $d_{\alpha}$ for steel B was noticed when the strain increased from 0.91 to 1.6 , which should be caused by the occurrence of CDRX of ferrite. Many researchers have reported the occurrence of CDRX of ferrite in the process of dynamic transformation either during interstitial rolling or in lab conditions, which develops through the progressive increase of sub-grain misorientations (low-angle grain boundaries, $2^{\circ} \leq \theta \leq 15^{\circ}$ ) into new grains (high-angle grain boundaries, $\theta>15^{\circ}$ ) rather than classical nucleation [23-25]. For the appearance of large particles, there can be elastic interaction with any stress fields surrounding the particles and these stress fields can attract the approaching dislocation, which induces the formation of the sub-grain boundary, as shown in Fig. 4 a. Meanwhile, fine precipitates easily form on the boundaries/dislocations due to low energy and the enrichment of solute atoms [26], which have a pinning effect. According to Ref. [27], precipitates can serve as very effective stabilizers for dislocation substructures and deformation bands developed, and consequently assist an increase in the misorientation of deformation-induced dislocation boundaries. Therefore, one can conclude that the large precipitates enhance the CDRX of ferrite during the process of dynamic transformation, and explain the greater tendency of $d_{\alpha}$ to decrease when the strain increased from 0.91 to 1.20 .

To prove this inference, boundary misorientation maps of steel B deformed at strains of 0.91 and 1.2, and the corresponding distributions of misorientation angles between ferrite grains are shown in Fig. 7. In Fig. 7, the fraction of LAGBs at a strain of 0.91 was larger than at the strain of 1.2, which indicated the occurrence of CDRX. With the increasing strain, these sub-grains developed into individual grains and the LAGBs changed rapidly into HAGBs. Therefore, the fraction of LAGBs reduced sharply (Fig. 7b, d) and finer grains were obtained at a strain of 1.2 (Fig. 6b). Furthermore, the comparison of $d_{\alpha}$ between steels $\mathrm{A}$ and $\mathrm{B}$ indicated that the $(\mathrm{Ti}, \mathrm{V})(\mathrm{C}, \mathrm{N})$ large precipitates promoted the occurrence of CDRX of ferrite, thus enhancing the grain refinement effect.

\section{Conclusions}

In summary, the pre-existence of Ti particles would be a significant position for $\mathrm{V}$ precipitation and provide an effective size for the formation of intragranular ferrite during a short deformation time. $\mathrm{V}$ precipitated in large precipitates could reach $35 \%$ of the total content when the strain was increased by 1.2 for $1.2 \mathrm{~s}$, which indicated that large $\mathrm{V}$ content could precipitate rapidly due to high $\mathrm{N}$ addition during dynamic transformation. The appearance of the large precipitates acted as the nuclear sites for ferrite and decreased the $\mathrm{V}$ dissolved in austenite, which dramatically promoted the dynamic transformation. The large precipitates accelerated the occurrence of CDRX of ferrite, which obviously enhanced the grain refinement.

Acknowledgments This work was financially supported by the National Natural Science Foundation of China (No. 51171162) and the Key R\&D Projects of Hebei Province (No. 09215139D).

\section{References}

[1] H. Yada, C.M. Li, H. Yamagata, ISIJ Int. 40, 200 (2000)

[2] N. Park, S. Khamsuk, A. Shibata, N. Tsuji, Scr. Mater. 68, 538 (2001)

[3] M.H. Cai, H. Ding, Y.K. Lee, Mater. Trans. JIM 52, 1722 (2011)

[4] B. Eghbali, A.A. Zadeh, Scr. Mater. 53, 41 (2005)

[5] Y. Adachi, M. Wakita, H. Beladi, P.D. Hodgson, Acta Mater. 55, 4925 (2007)

[6] Z.Q. Sun, W.Y. Yang, A.M. Hu, P. Yang, Acta Metall. Sin. (Engl. Lett.) 14, 115 (2001)

[7] J. Hu, L.X. Du, J.J. Wang, C.R. Gao, T.Z. Yang, A.Y. Wang, R.D.K. Misra, Mater. Trans. A 44, 4937 (2013)

[8] B. Eghbali, A. Abdollah-Zadeh, Mater. Des. 28, 1021 (2007)

[9] K. Wang, L.J. Wang, W.F. Cui, C.M. Liu, J. Mater. Sci. Technol. 22, 159 (2006)

[10] S.F. Medina, M. Gómez, L. Rancel, Scr. Mater. 58, 1110 (2008)

[11] J. Hu, L.X. Du, J.J. Wang, Scr. Mater. 68, 953 (2013)

[12] J.H. Shim, Y.W. Cho, S.H. Chung, J.D. Shim, D.N. Lee, Acta Mater. 47, 2751 (1999)

[13] T. Furuhara, J. Yamaguchi, N. Sugita, G. Miyamoto, T. Maki, ISIJ Int. 43, 1630 (2003)

[14] S.G. Hong, K.B. Kang, C.G. Park, Scr. Mater. 46, 163 (2002)

[15] J.G. Jung, J.S. Park, J. Kim, Y.K. Lee, Mater. Sci. Eng. A 528, $5529(2011)$

[16] K.A. Taylor, Scr. Metall. Mater. 32, 7 (1995)

[17] K. Narita, ISIJ Int. 15, 145-151 (1975)

[18] X.G. Zhou, Z.Y. Liu, D. Wu, Z. Li, C.M. Li, Acta Metall. Sin. (Engl. Lett.) 19, 385 (2006)

[19] J.M. Gregg, H.K.D.H. Bhadeshia, Acta Mater. 45, 739 (1997)

[20] J.H. Shim, Y.J. Oh, J.Y. Suh, Y.W. Cho, J.D. Shim, J.S. Byun, D.N. Lee, Acta Mater. 49, 2115 (2001)

[21] M. Enomoto, N. Nojiri, Y. Sato, Mater. Trans. JIM 35, 859 (1994)

[22] C.W. Zheng, N.M. Xiao, L.H. Hao, D.Z. Li, Y.Y. Li, Acta Mater. 57, 2956 (2009)

[23] A. Abdollah-Zadeh, B. Eghbali, Mater. Sci. Eng. A 57, 219 (2007)

[24] S. Gourdet, F. Montheillet, Acta Mater. 51, 2685 (2003)

[25] A. Shokouhi, P.D. Hodgson, Mater. Sci. Technol. 23, 1233 (2007)

[26] S.Q. Yuan, S.W. Yang, W.J. Nie, X.L. He, Acta Metall. Sin. 40, 887 (2004). (in Chinese)

[27] R. Kaibyshev, O. Sitdikov, A. Goloborodko, T. Sakai, Mater. Sci. Eng. A 344, 348 (2003) 